\title{
Effect of Deformation Temperature on the Portevin-Le Chatelier Effect in Medium-Mn Steel
}

\author{
Barbara Grzegorczyk ${ }^{1}$, Aleksandra Kozłowska ${ }^{1}$ (), Mateusz Morawiec ${ }^{1}$, Rafał Muszyński ${ }^{2}$ \\ and Adam Grajcar ${ }^{1, *(D)}$ \\ 1 Silesian University of Technology, Faculty of Mechanical Engineering, 18a Konarskiego Street, \\ 44-100 Gliwice, Poland; barbara.grzegorczyk@polsl.pl (B.G.); aleksandra.kozlowska@polsl.pl (A.K.); \\ mateusz.morawiec@polsl.pl (M.M.) \\ 2 Premco Logistics, 15/I/6 3 maja street, 41-200 Sosnowiec, Poland; rafal.muszynski@premco.eu \\ * Correspondence: adam.grajcar@polsl.pl; Tel.: +48-32-237-2933
}

Received: 24 November 2018; Accepted: 18 December 2018; Published: 20 December 2018

\begin{abstract}
Experimental investigations of the plastic instability phenomenon in a hot-rolled medium manganese steel were performed. The effects of tensile deformation in a temperature range of 20-140 ${ }^{\circ} \mathrm{C}$ on the microstructure, mechanical properties, and flow stress serrations were analyzed. The Portevin-Le Chatelier (PLC) phenomenon was observed for the specimens deformed at $60^{\circ} \mathrm{C}$, $100{ }^{\circ} \mathrm{C}$, and $140{ }^{\circ} \mathrm{C}$. It was found that the deformation temperature substantially affects the type and intensity of serrations. The type of serration was changed at different deformation temperatures. The phenomenon was not observed at room temperature. The plastic instability occurring for the steel deformed at $60^{\circ} \mathrm{C}$ was detected for lower strain levels than for the specimens deformed at $100{ }^{\circ} \mathrm{C}$ and $140{ }^{\circ} \mathrm{C}$. The increase of the deformation temperature to $100^{\circ} \mathrm{C}$ and $140{ }^{\circ} \mathrm{C}$ results in shifting the PLC effect to a post uniform deformation range. The complex issues related to the interaction of work hardening, the transformation induced plasticity (TRIP) effect, and the PLC effect stimulated by the deformation temperature were addressed.
\end{abstract}

Keywords: medium-Mn steel; retained austenite; Portevin-Le Chatelier phenomenon; strain-induced martensitic transformation; ultra-high strength steel

\section{Introduction}

A growing interest in medium manganese steels related to their advantageous strength-ductility balance has prompted a better understanding of their behavior during plastic deformation [1-4]. Medium manganese steels contain 3-12\% Mn and other alloying additions, such as $\mathrm{Al}$ and $\mathrm{Si}$. In the present work, Mo addition is also added due to its strong solid solution strengthening potential [3]. Low-C (i.e., $\sim 0.1 \%$ ) steels containing $\sim 3 \%$ Mn show ferritic-martensitic microstructures in the initial state [1]. When the manganese content rises, the initial microstructure (after cold rolling) changes to low-C martensite [2]. Medium-Mn steels can be obtained as cold-rolled [5] or hot-rolled [6] sheets. For lightweight applications in the automotive industry, cold-rolled coated sheet products are of particular interest. In order to obtain the multiphase microstructure consisting of ferrite and austenite or bainite and austenite, intercritical annealing is required $[5,7]$. These steels can be also produced as hot-rolled sheets for some underbody/suspension applications. After the hot-working and cooling to room temperature (a quenching step), the martensitic or ferritic-martensitic microstructure is subjected to intercritical annealing. The fine-grained lath-type ferrite-austenite mixture is formed under such annealing conditions [6]. For such small grain sizes of the austenite and its Mn contents higher than $7 \%$, the stable austenite is retained at room temperature. For smaller Mn contents (i.e., for higher martensite start temperatures), an isothermal holding step at a bainitic range is required to be able to 
stabilize the retained austenite through its carbon enrichment [8]. An alternative approach is to apply thermomechanical processing (TMP) as direct one-step cooling following the hot rolling. The TMP has the potential for energy savings and high productivity due to the elimination of the need for successive heating [9-11]. Chemical composition and processing parameters are designed to obtain the optimal TRIP (Transformation Induced Plasticity) effect, which ensures superior mechanical properties [12,13].

Besides the many advantages of this group of steels, some problems during their processing can occur. Medium manganese steels [14-17] and high manganese steels [18-20] are prone to plastic instabilities phenomena associated with a serrated flow behavior-Portevin-Le Chatelier (PLC) effect and the appearance of Lüders bands. This is especially the case for cold-rolled steel sheets [21]. Moreover, it critically depends on the carbon level. With a higher $C$ content, a pronounced effect is more visible. The heterogeneous deformation related to the increase in flow stress can lead to numerous cracks during the forming of sheets. Moreover, delayed cracking after deep drawing can appear. Delayed cracking is mostly observed in high-Mn content steels of the high austenite volume fraction. With the increased volume fraction of (retained) austenite, hydrogen embrittlement may be a more important concern. TWIP steels in the last decades have displayed important delayed cracking, which was industrially solved by decreasing the $\mathrm{C}$ content, $\mathrm{Al}$ alloying, and / or metallurgical processing [22,23]. Medium Mn steels have a less pronounced problem of delayed cracking compared to high-Mn steels $[24,25]$.

The PLC effect is commonly known as characteristic serrations which can be observed on a strain-stress curve during a tensile test. The PLC effect has not been fully characterized yet. However, some correlations between the TRIP and PLC effects were recently documented in the literature. Gibbs et al. [26] proposed the theory that the characteristic serration is related to the various martensitic transformation rates during plastic deformation. Callahan et al. [14] observed that the TRIP effect and the passage of both Lüders and PLC bands occur simultaneously in 0.2C-5Mn-2.5Al medium-Mn steel. Sun et al. [15] reported that plastic instability in $0.26 \mathrm{C}-11.6 \mathrm{Mn}-2.7 \mathrm{Al}$ steel was related to discontinuous strain-induced martensite transformation. They observed localized martensite formation in the PLC bands, which propagated during tensile straining. It seems that twinning should also have some impact, taking into account the stacking fault energy of the alloy and its resulting increased austenite stability. Experimental results obtained by other authors $[20,27,28]$ confirmed that the chemical composition of steel (especially $\mathrm{C}$ and Mn contents), deformation temperature, and strain rate had an influence on the occurrence of the PLC effect and the mechanical stability of the retained austenite.

So far, the PLC effect has been intensively studied in aluminium- and copper-based alloys [29-31]. Recently, this phenomenon was also largely studied in TWIP steels [18-20,22,23]. There are numerous theories explaining this effect. The most important factor is the interaction between dislocations and segregating $\mathrm{C}$ atoms. The occurrence of the PLC effect results in the appearance of technological problems during plastic forming. The characterization of factors affecting the PLC effect in medium-Mn steels is important both from a scientific point of view and their industrial application. Therefore, the goal of the current study is to identify the work hardening behavior of thermomechanically processed medium-Mn steel in terms of the PLC effect stimulated by a deformation temperature.

\section{Material and Methods}

\subsection{Material}

The chemical composition of the investigated steel is shown in Table 1. It is well-known [32,33] that an increased carbon content deteriorates the steel weldability. Moreover, the probability of the occurrence of the PLC effect becomes higher [19]. Hence, a relatively low carbon content of the investigated steel (0.16 wt.\%) was designed. Manganese content also affects the PLC effect [34]. The tested steel contains $\sim 5 \mathrm{wt} . \% \mathrm{Mn}$ due to its application for hot-rolled products. The higher $\mathrm{Mn}$ contents are usually used for cold-rolled products [1,35]. Aluminium was chosen to prevent carbide precipitation. 
The investigated steel was prepared by vacuum induction melting. Then, the laboratory ingots were hot-forged to obtain flat samples with a thickness of $22 \mathrm{~mm}$. The next steps included roughing rolling and the thermomechanical rolling process.

Table 1. Chemical composition of the investigated medium-Mn steel in wt.\%.

\begin{tabular}{ccccccc}
\hline $\mathbf{C} \%$ & Mn \% & Al \% & Si \% & Mo \% & P \% & S \% \\
\hline 0.16 & 4.7 & 1.6 & 0.22 & 0.20 & 0.008 & 0.004 \\
\hline
\end{tabular}

\subsection{Thermomechanical Rolling}

The thermomechanical laboratory rolling included three passes. The final sheet thickness was about $4.5 \mathrm{~mm}$. Figure 1 shows the applied hot-rolling conditions. The austenitization was carried out at $1200^{\circ} \mathrm{C}$. The temperature of the final pass was about $850^{\circ} \mathrm{C}$. Then, the flat steel samples were cooled to $400{ }^{\circ} \mathrm{C}$ and held at this temperature for $300 \mathrm{~s}$. Finally, air cooling to room temperature was applied.

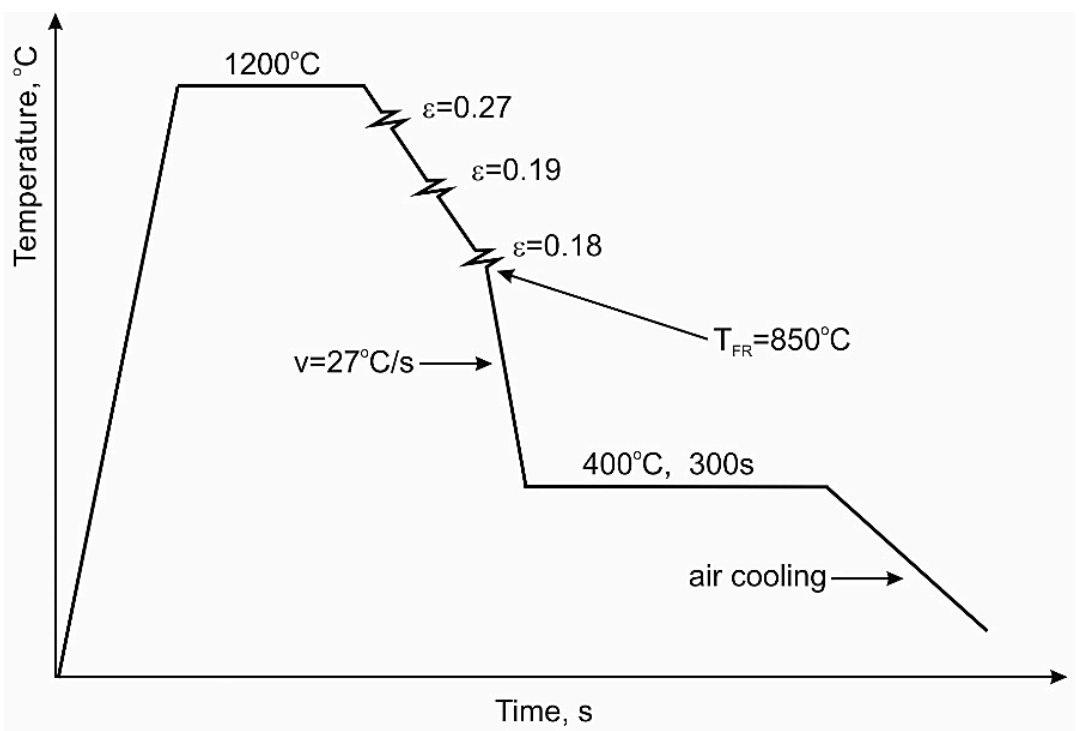

Figure 1. Parameters of thermomechanical processing of investigated steel.

\subsection{Experimental Procedures}

The tensile tests were performed at $20^{\circ} \mathrm{C}$ and at elevated temperatures: $60^{\circ} \mathrm{C}, 100{ }^{\circ} \mathrm{C}$, and $140{ }^{\circ} \mathrm{C}$, to determine the effect of deformation temperature on the PLC effect and the related microstructure and mechanical properties. Tensile specimens were machined from the hot-rolled sheet along the rolling direction. Three uniaxial tensile tests were carried out for each temperature using an INSTRON 1195 universal testing machine (INSTRON, Norwood, MA, USA )at a strain rate of $10^{-3} \mathrm{~s}^{-1}$. The results of tensile tests allowed us to determine the effect of deformation temperature on the mechanical properties. A determination of the work hardening rate allowed us to establish the influence of the TRIP effect on the strengthening behavior. Based on $\sigma-\varepsilon$ curves, classification of the strengthening stages and types of oscillations was conducted. The value of the critical strain, required for the initiation of the PLC effect, was also determined.

The microstructural analysis was performed for the steel samples tensile tested at different temperatures. The observations were carried out using the Zeiss Axio Observer Z1m optical microscope (Carl Zeiss AG, Jena, Germany). The microstructural details were revealed with a scanning electron microscope Zeiss SUPRA 25 (Carl Zeiss AG, Jena, Germany) operating at $20 \mathrm{kV}$, working in SE mode. Specimens for microstructural observations were prepared using standard metallographic procedures. They were mechanically ground with $\mathrm{SiC}$ paper up to $2000 \mathrm{grid}$, then polished with a diamond paste and finally etched in $5 \%$ nital. 


\section{Results}

\subsection{Mechanical Behavior}

Results of static tensile tests (average values of three samples) performed at various temperatures: $20{ }^{\circ} \mathrm{C}, 60^{\circ} \mathrm{C}, 100{ }^{\circ} \mathrm{C}$, and $140^{\circ} \mathrm{C}$, are listed in Table 2 and presented in Figure 2.

Table 2. Mechanical properties of the investigated steel.

\begin{tabular}{ccccc}
\hline Deformation Temperature $\left[{ }^{\circ} \mathrm{C}\right]$ & UTS [MPa] & YS [MPa] & TE [\%] & YS/UTS [MPa] \\
\hline 20 & 1215 & 882 & 11.5 & 0.73 \\
60 & 1200 & 856 & 10.3 & 0.71 \\
100 & 1180 & 873 & 9.8 & 0.74 \\
140 & 1223 & 841 & 11.4 & 0.69 \\
\hline
\end{tabular}

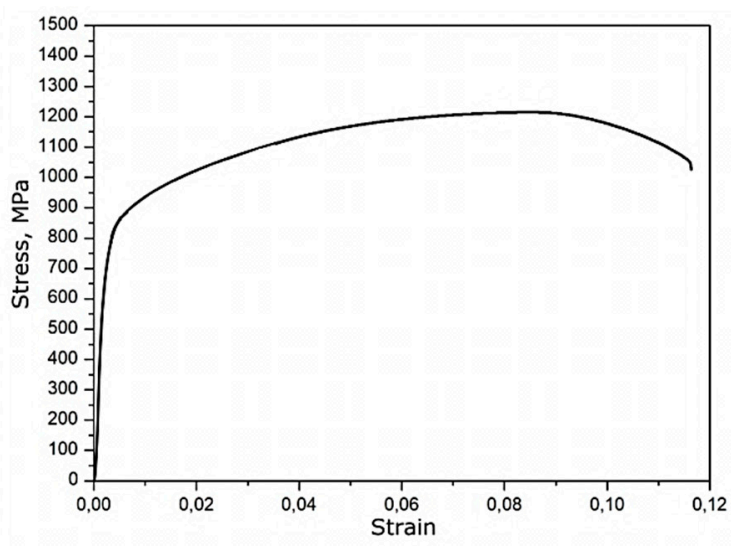

(a)

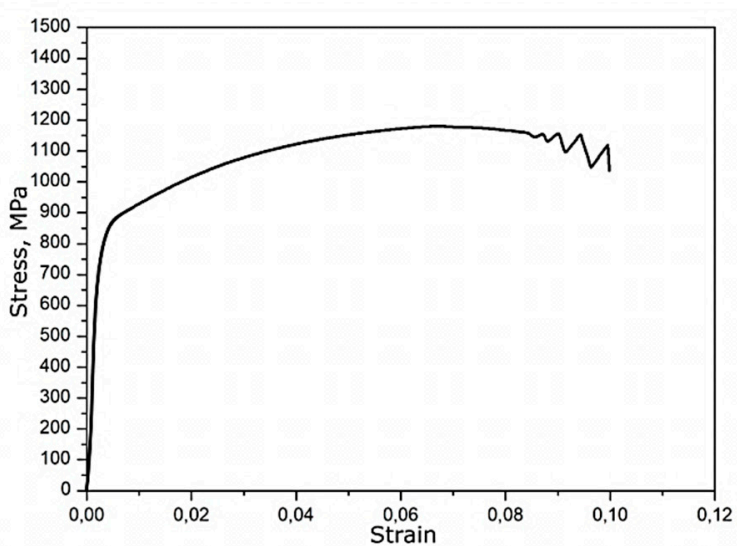

(c)

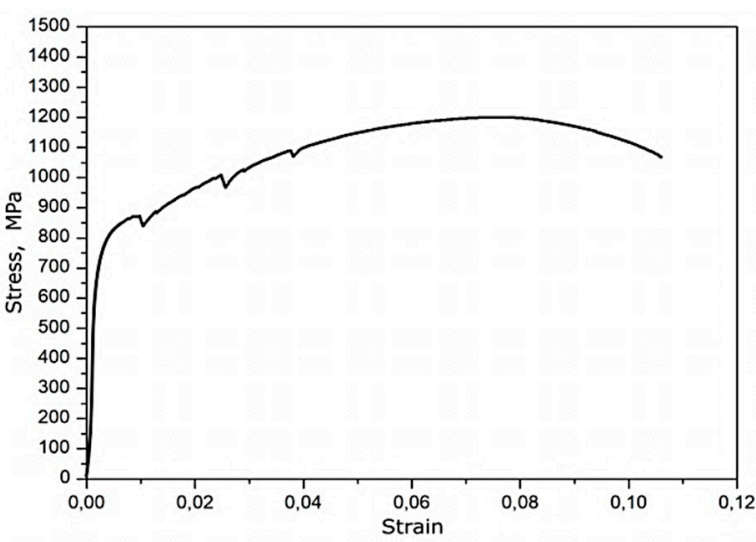

(b)

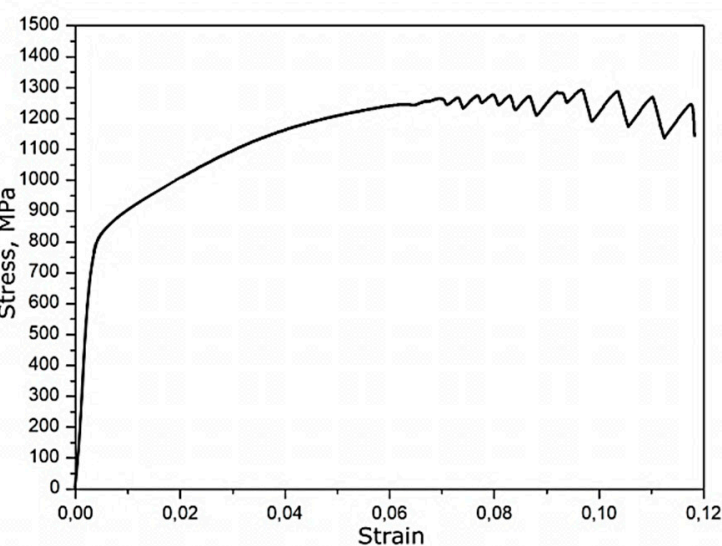

(d)

Figure 2. Engineering stress-strain curves of investigated steel registered at: (a) $20^{\circ} \mathrm{C}$, (b) $60{ }^{\circ} \mathrm{C}$, (c) $100{ }^{\circ} \mathrm{C}$, and (d) $140{ }^{\circ} \mathrm{C}$.

Based on the obtained data, a pronounced relationship between the deformation temperature and mechanical properties was observed. The sample deformed at $20{ }^{\circ} \mathrm{C}$ shows relatively high mechanical properties. The tensile strength (UTS) and yield stress (YS) values are $1215 \mathrm{MPa}$ and $882 \mathrm{MPa}$, respectively (Table 2). The highest total elongation (TE) value was obtained at this deformation temperature $-11.5 \%$. The YS/UTS ratio is 0.73 , which indicates the relatively high hardening potential. Increasing the deformation temperature to $60{ }^{\circ} \mathrm{C}$ results in slight lowering of both UTS and YS values 
(UTS = $1200 \mathrm{MPa} ; \mathrm{YS}=856 \mathrm{MPa})$. The TE value is also a little bit lower $(10.3 \%)$. The YS/UTS ratio is quite similar to that obtained at the lower deformation temperature. At $100{ }^{\circ} \mathrm{C}$, a similar yield stress is obtained. The tensile strength $(1180 \mathrm{MPa})$ is slightly lower as a result of smaller work hardening. A further deterioration of TE was detected $(9.8 \%)$. Surprisingly, the highest UTS value (1223 MPa) was obtained for the specimen deformed at $140{ }^{\circ} \mathrm{C}$. The YS/UTS ratio in this case is 0.69 , which indicates the relatively high strengthening potential. As a result, the TE value was about $11.4 \%$, which is similar to the TE value obtained for the sample deformed at $20^{\circ} \mathrm{C}$ (Table 2).

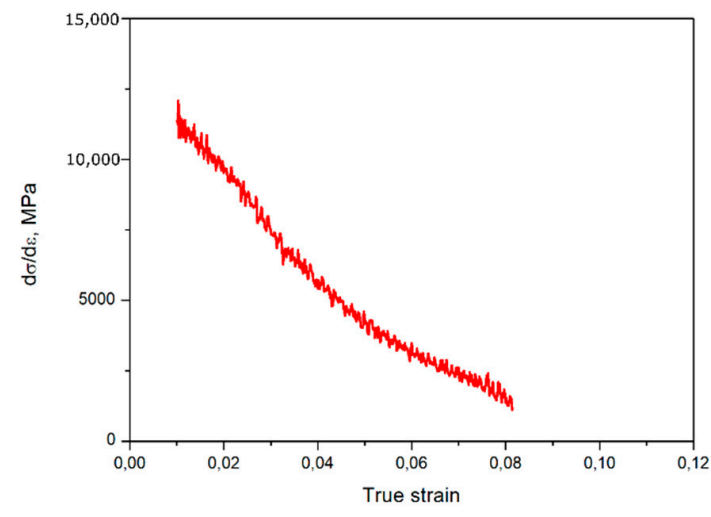

(a)

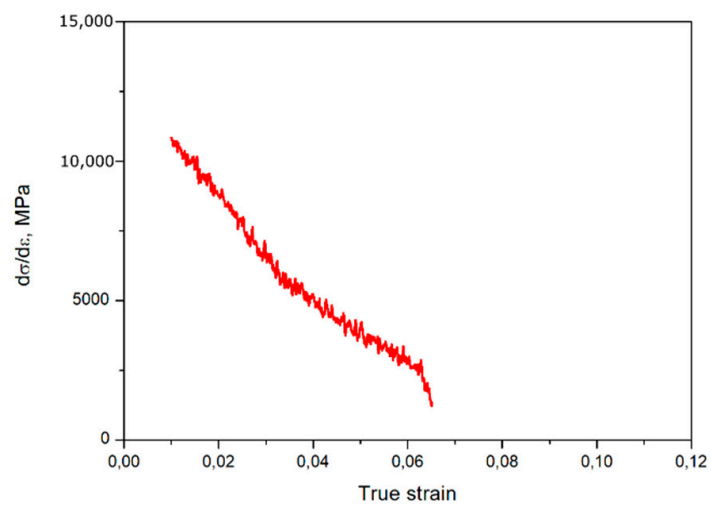

(c)

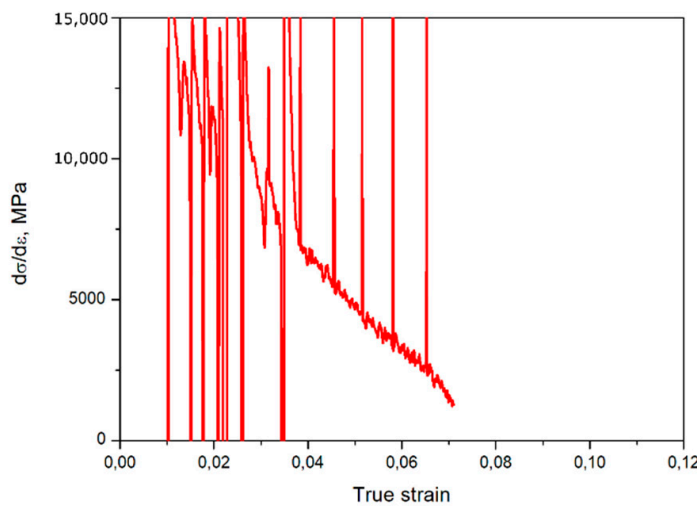

(b)

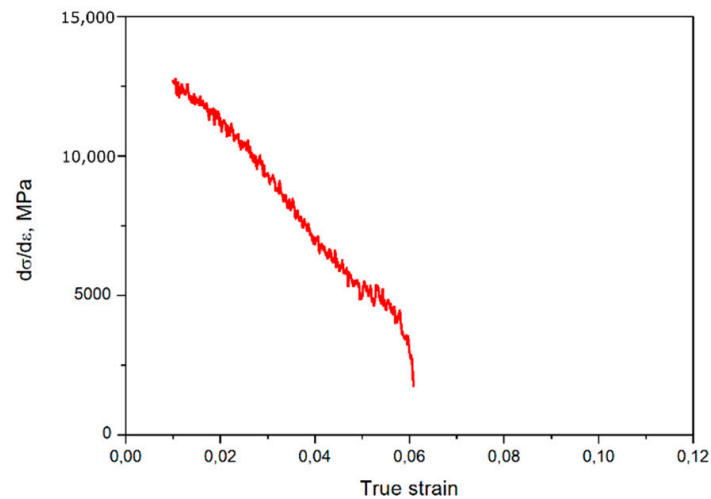

(d)

Figure 3. Work hardening rate as a function of true strain (uniform deformation range) at: (a) $20^{\circ} \mathrm{C}$, (b) $60{ }^{\circ} \mathrm{C}$, (c) $100{ }^{\circ} \mathrm{C}$, and (d) $140{ }^{\circ} \mathrm{C}$.

Some typical features for the PLC effect $[14-20,28]$ were observed for the investigated steel deformed at elevated temperatures: $60-140{ }^{\circ} \mathrm{C}$. The characteristic serrations were observed on the stress-strain curves (Figure 2). The specimen deformed at $20^{\circ} \mathrm{C}$ showed no evidence of the PLC effect (Figure 2a). Increasing the deformation temperature to $60^{\circ} \mathrm{C}$ resulted in the appearance of serrations in the initial stage of plastic deformation (Figure 2b). Observed oscillations were classified as A type according to the nomenclature given in previous works [36,37]. The stress oscillation occurs periodically on the graph line after the yield point. The range of deformation when serration occurred is variable. In contrast, for the specimens deformed at $100{ }^{\circ} \mathrm{C}$ and $140{ }^{\circ} \mathrm{C}$, the oscillations were observed in the final stage of deformation (Figure 2c,d). The serrations were observed in the range of post-uniform deformation. The shape of the serrations at $100{ }^{\circ} \mathrm{C}$ corresponds to the type B [36]. Increasing the deformation temperature to $140{ }^{\circ} \mathrm{C}$ results in intensifying the serration amplitude and plastic deformation range. This occurred in the whole range of post-uniform elongation (Figure 2d). After the strain of ca. 0.08 , the B+C type oscillations [37] can be observed. The corresponding increase of TE to $11.4 \%$ should be related to the enhanced occurrence of oscillations due to the PLC effect. Generally, the important influence of the deformation temperature on the oscillation type and its 
intensity was observed. In the literature $[14,15,17]$, the mechanism of plastic instability phenomenon associated with the Portevin-Le Chatelier effect in Fe-Mn alloys at an elevated temperature is generally attributed to a dynamic strain aging (DSA) effect.

The deformation temperature strongly affects the work hardening rate of the investigated steel (Figure 3). The $\mathrm{d} \sigma / \mathrm{d} \varepsilon$ values decrease gradually as the deformation degree increases. This behavior is typical. In steels with a high volume fraction of metastable retained austenite, a local increase in the $\mathrm{d} \sigma / \mathrm{d} \varepsilon$ value can be observed $[2,13]$ due to the intense TRIP effect. This is not the case for the present steels. The smallest slope of the curves was observed for the steel deformed at $20^{\circ} \mathrm{C}$ (Figure 3a). When increasing the deformation temperature from $20^{\circ} \mathrm{C}$ to $140{ }^{\circ} \mathrm{C}$, a general slope of the $\mathrm{d} \sigma / \mathrm{d} \varepsilon-\varepsilon$ curves rises. It is consistent with the gradual decrease of true strain in a range of uniform deformation: from 0.08 at $20{ }^{\circ} \mathrm{C}$ to 0.06 at $140{ }^{\circ} \mathrm{C}$. The different course of the curve in Figure $3 \mathrm{~b}$ is related to the appearance of the PLC effect in the early stages of uniform strain. In this case, the work hardening rate is strongly irregular due to the serrations occurring in the tensile curve. The lowest work hardening rate was detected for the steel deformed at $100{ }^{\circ} \mathrm{C}(11000 \mathrm{MPa})$. The work hardening rate was similar for the specimens deformed at $20^{\circ} \mathrm{C}$ and $140{ }^{\circ} \mathrm{C}$. This means that some thermally activated ageing processes are enhanced after the rise in temperature to $140^{\circ} \mathrm{C}$.

Mechanical properties of the steels were also assessed by hardness tests using the Vickers method. The obtained results are presented in Figure 4. It is clear that hardness values are affected by the deformation temperature. They are at a relatively high level taking into account the carbon content in the steel $(490-530 \mathrm{HV})$. The lowest hardness was detected for the specimen in a hot-rolled state. All the hardness results were higher for plastically deformed samples. It was found that the highest hardness was obtained for the sample tensile tested at room temperature. Then, the hardness decreases when increasing the deformation temperature. The presented results are in reasonable agreement with the mechanical properties obtained from the static tensile tests (Table 2). Some variations could be due to the different intensity of the TRIP effect and PLC effect at different temperatures.

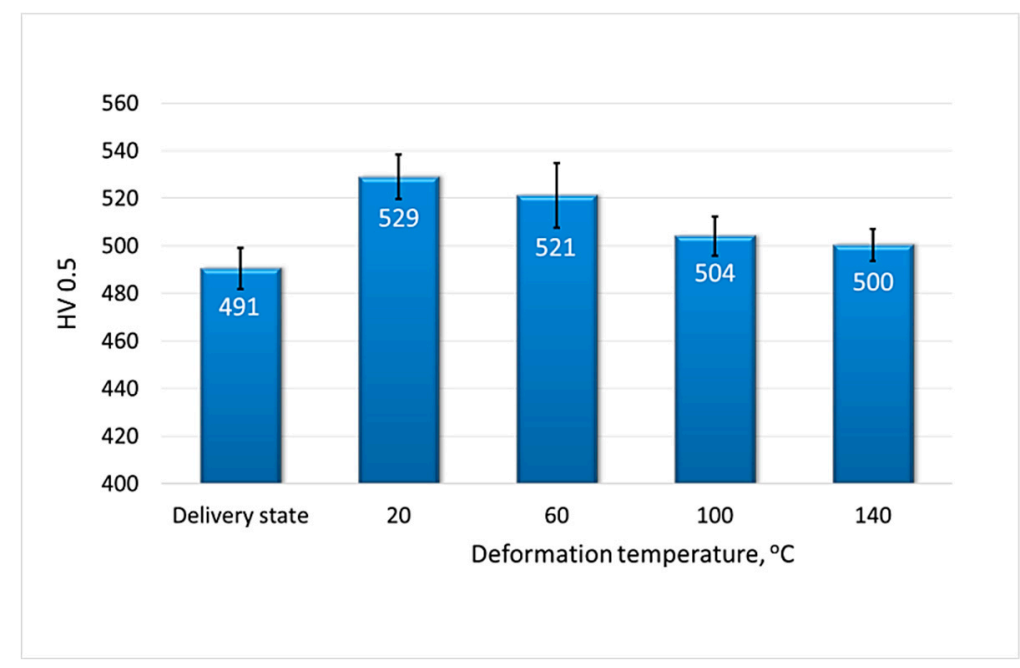

Figure 4. Effect of deformation temperature on the hardness.

\subsection{Microstructure}

Results of metallographic observations allowed us to determine the microstructure of the investigated steel in the delivery state (after hot rolling) and after the tensile test. Optical micrographs for selected deformation temperatures are shown in Figure 5. The hot-rolled 5Mn steel (in the delivery state) is characterized by a mixture of bainite and martensite (Figure 5a). At this magnification, it is hard to assess the presence of retained austenite. However, the amount of this phase determined in our previous works $[8,38]$ by XRD methods is equal to $\sim 10 \%$. The microstructures registered 
after the plastic deformation in a temperature range of $20-140{ }^{\circ} \mathrm{C}$ are very similar. Fine laths of bainitic-martensitic products are visible (Figure $5 b-d$ ).

The identification of retained austenite in the microstructure of $5 \mathrm{Mn}$ steel is difficult due to its relatively small amount. It is related to the manganese content ( $5 \mathrm{wt} . \%$ ), which affects the carbon content level in the retained austenite. As the manganese content increases, the carbon content in the $\gamma$ phase decreases [39-41]. This was recently confirmed by Sugimoto et. al [1] in medium-Mn steels containing 1.5 to $5 \% \mathrm{Mn}$.

(a)

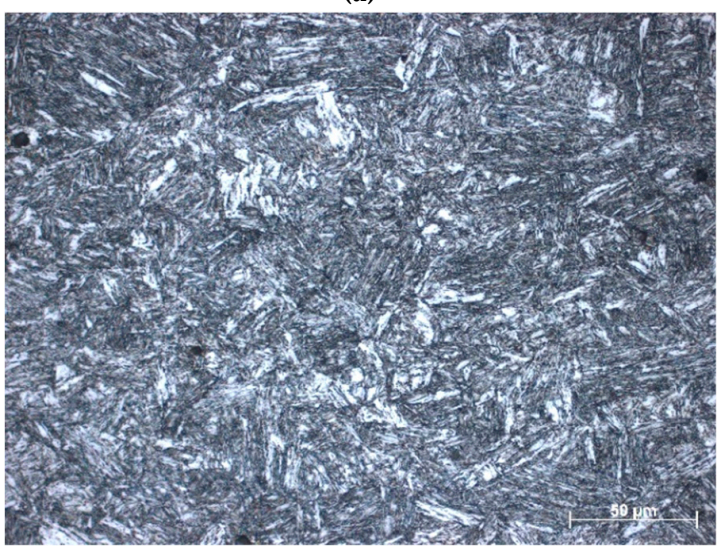

(c)

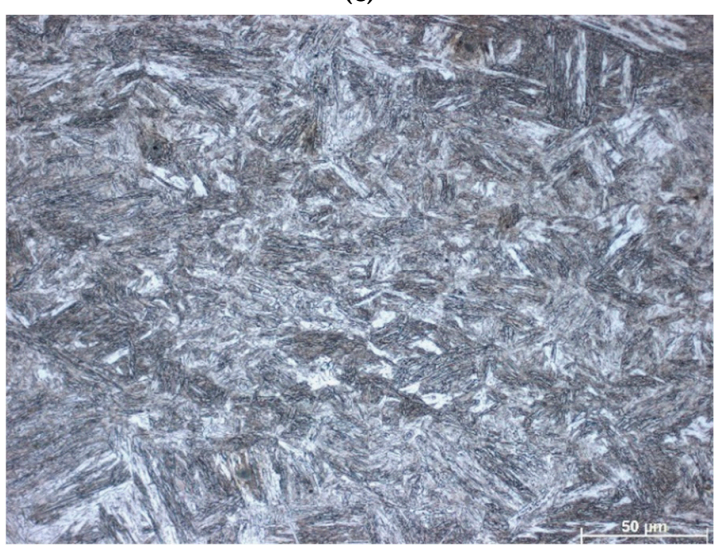

(b)

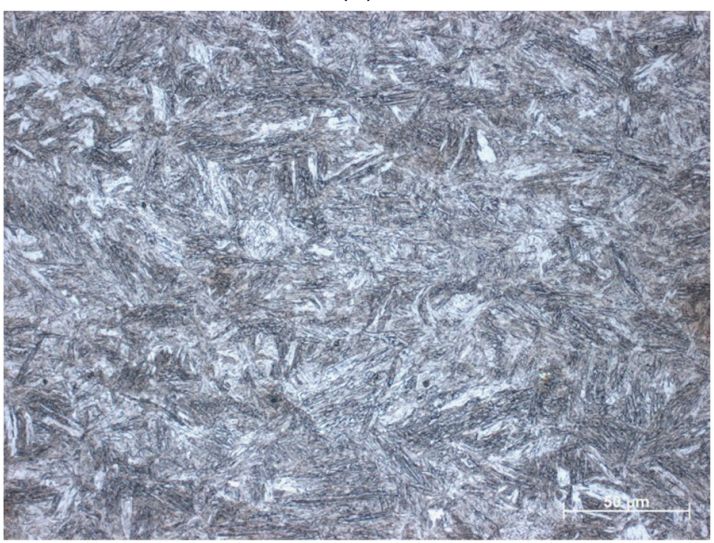

(d)

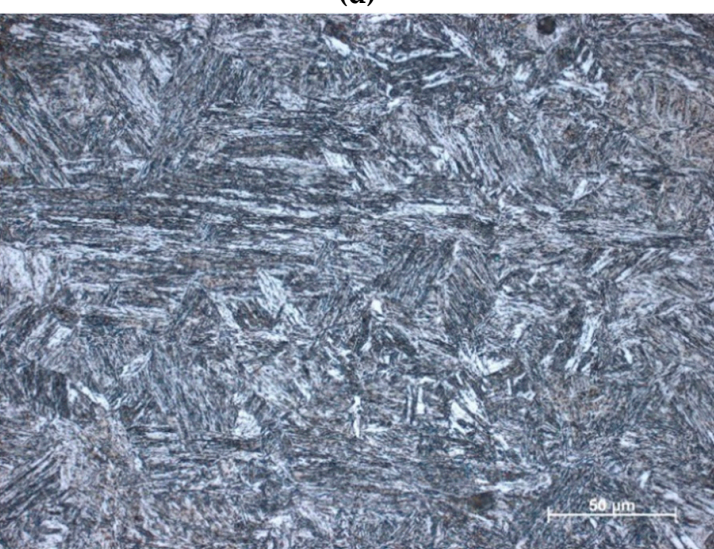

(e)

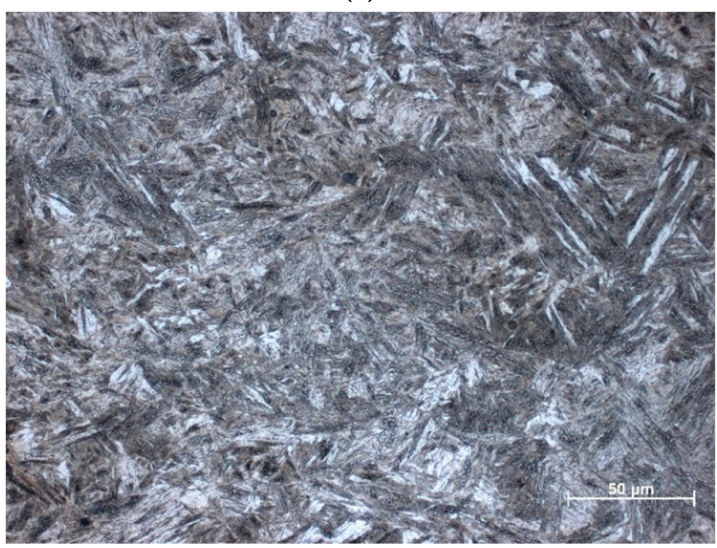

Figure 5. Optical micrographs of the investigated steel: (a) delivery state; deformed at: (b) $20{ }^{\circ} \mathrm{C}$, (c) $60^{\circ} \mathrm{C}$, (d) $100{ }^{\circ} \mathrm{C}$, and (e) $140{ }^{\circ} \mathrm{C}$. 


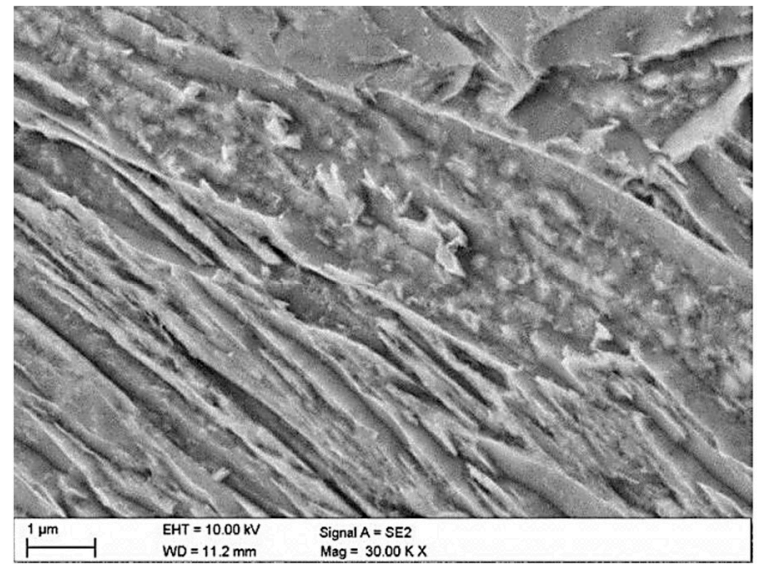

(a)

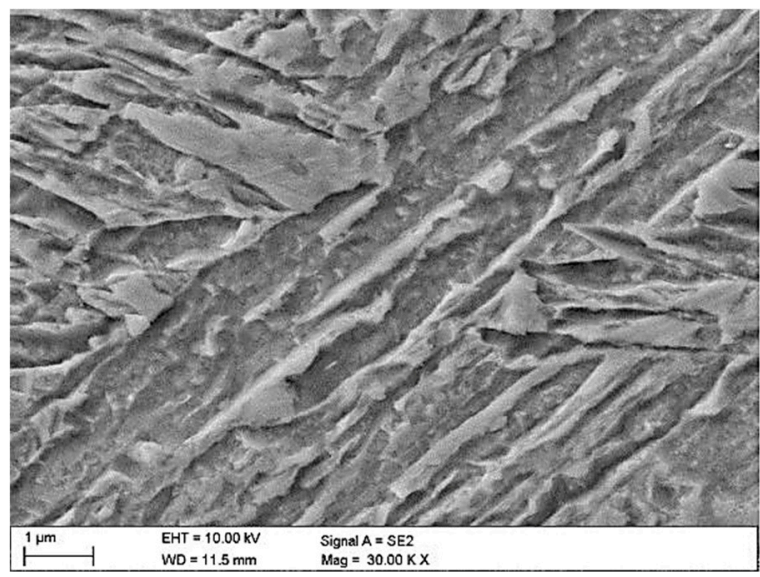

(c)

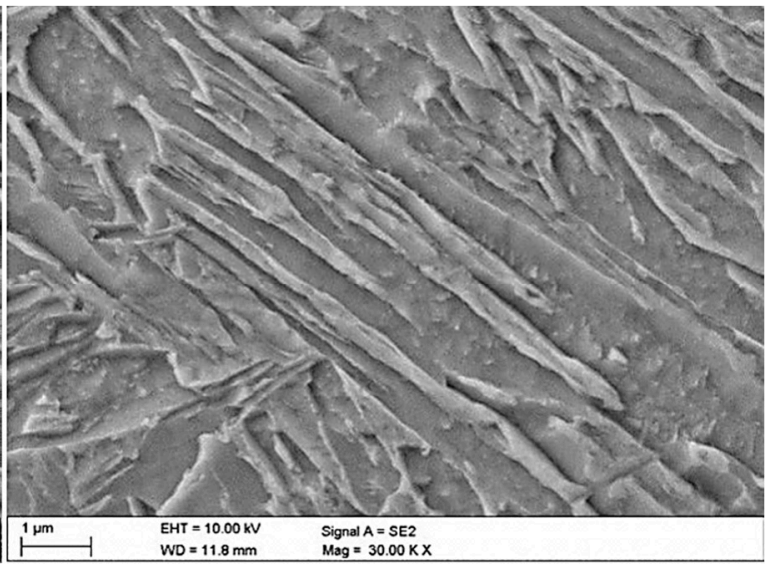

(b)

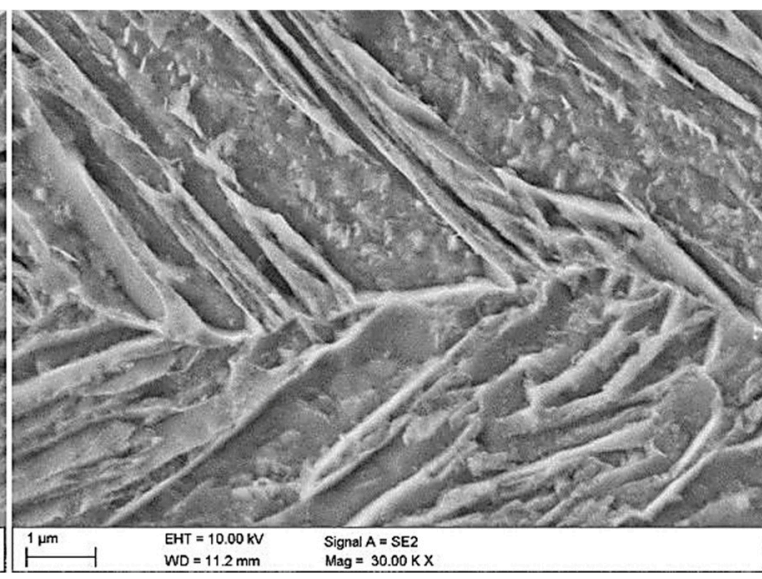

(d)

Figure 6. SEM micrographs of the $5 \mathrm{Mn}$ steel deformed at: (a) $20^{\circ} \mathrm{C},(\mathbf{b}) 60^{\circ} \mathrm{C}$, (c) $100^{\circ} \mathrm{C}$, and (d) $140{ }^{\circ} \mathrm{C}$.

SEM observations confirmed the presence of the lath-type martensitic-bainitic microstructure (Figure 6). Bright, thin layers observed in the microstructure are probably the remains of retained austenite [8,38]. This metastable phase is partially transformed into strain-induced martensite. However, this requires more detailed microscopic investigations. The laths have various thicknesses. Inside the bainitic areas, small precipitates characterized by a different shape can also be identified. This indicates the initiation of carbide precipitation during the isothermal holding step following the hot rolling.

\section{Discussion}

Plastic deformation of medium manganese steels with a multiphase microstructure is very complex. The deformation of these steels is related to the specific microstructural mechanisms, like transformation induced plasticity (TRIP) and Portevin-Le Chatelier (PLC) effects. The occurrence of the PLC effect was previously typically observed in $\mathrm{Al}$ and $\mathrm{Cu}$ alloys at room or elevated temperatures [29-31]. Concerning steels, the serrated behavior in flow stress was observed in dual-phase steels [42], quenching and partitioning steels [28], and recently in high manganese twinning induced plasticity (TWIP) steels containing 17-25\% Mn [18-20,23,27,43]. Increasing the Mn content reduces the diffusion rate of carbon [44]. That is why the PLC effect is so pronounced in TWIP steels. However, recent studies proved that it also takes place in medium-Mn steels [15,24,25]. This process usually takes place in a range of specific temperatures and strain rates. An explanation of the PLC phenomenon in medium manganese steels seems to be a difficult issue due to the multiphase 
microstructure and the corresponding occurrence of the TRIP effect during plastic deformation. The temperature effect makes the analysis more advanced.

So far, in the literature, there are only a few reports available concerning the PLC effect in medium manganese steels [14-17,21,24]. Most of them concern cold rolled-steels. The PLC effect in hot-rolled medium Mn steels has rarely been analyzed [25]. Based on the data available in the literature and results obtained in the present study, one can conclude that the first difference exists in the yield point. In contrast to cold-rolled and intercritically annealed steels, the thermomechanically processed steels did not show evidence of high and low yield stress and subsequent Lüders elongation. This is the case for intercritically annealed steels $[14,16]$ and can be a real industrial problem during stamping, etc. The present steels show a continuous yielding behavior as a result of the mobile dislocations generated during previous thermomechanical processing. This was shown in our previous works $[8,38]$.

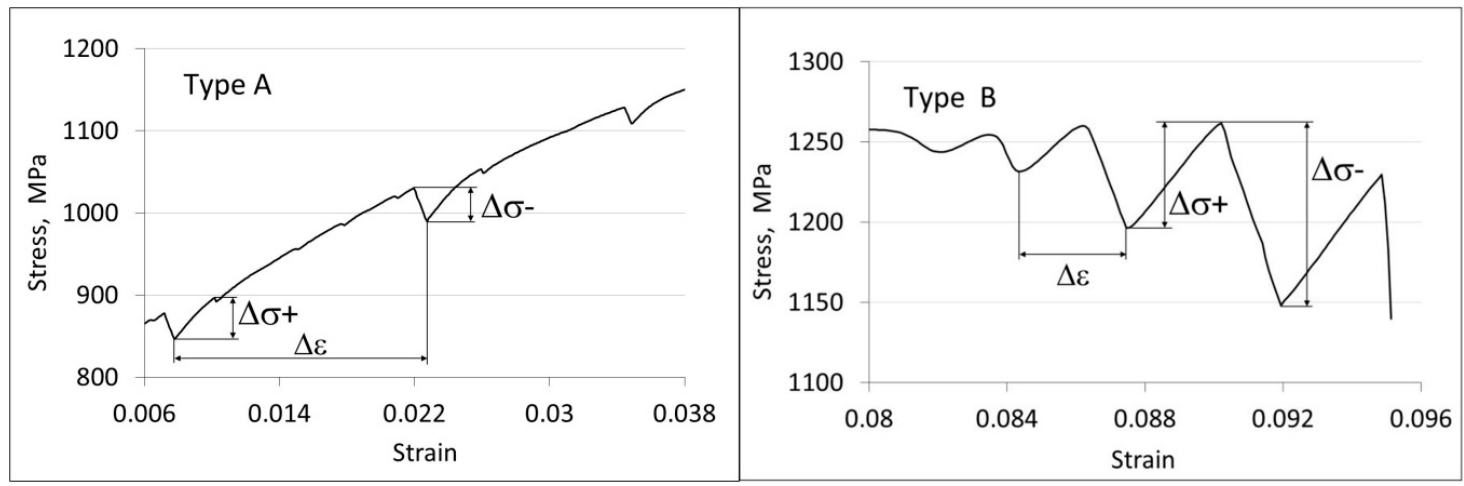

(a)

(b)

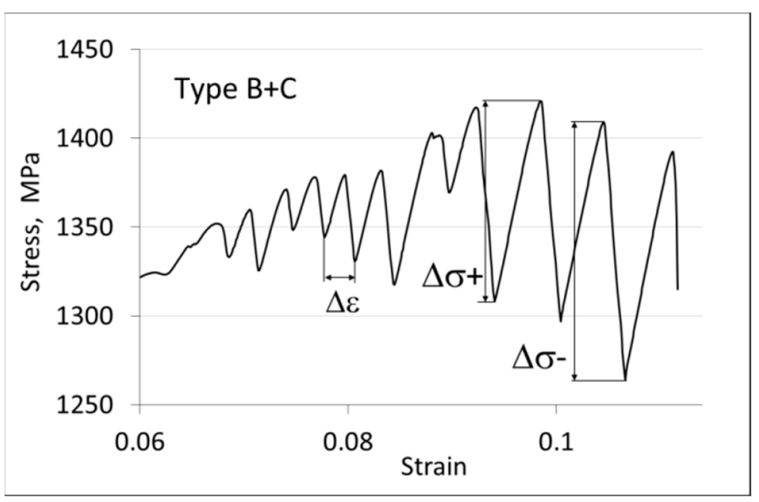

(c)

Figure 7. Details of serrations at the flow curves for the steel deformed at: $60{ }^{\circ} \mathrm{C}(\mathbf{a}), 100{ }^{\circ} \mathrm{C}(\mathbf{b})$, and $140{ }^{\circ} \mathrm{C}(\mathbf{c})$.

Results obtained in the present study showed that the temperature factor has a significant influence on the PLC occurrence. The steel deformed at $20{ }^{\circ} \mathrm{C}$ showed no evidence of plastic instability (Figure 2a). Characteristic serrations were detected at elevated deformation temperatures: $60^{\circ} \mathrm{C}$, $100{ }^{\circ} \mathrm{C}$, and $140{ }^{\circ} \mathrm{C}$ (Figure $2 \mathrm{~b}-\mathrm{d}$ ). It is interesting that the type of oscillations and their amplitude substantially depend on the deformation temperature. The specimen deformed at $60{ }^{\circ} \mathrm{C}$ showed oscillation classified as an A type. The serration occurred in a uniform elongation range, i.e., earlier than in steels deformed at higher temperatures-already at a strain level of 0.006 . Moreover, this appeared regularly and its amplitude was quite low (Figure 7a). A similar type of serration was observed in medium-Mn steels by other authors [14,15]. However, the type of serration and plastic instability deformation range shifted to a higher deformation level when increasing the deformation 
temperature. The instable flow behavior was initiated in a post-uniform elongation range. Moreover, the amplitude of serration rose as the deformation temperature increased (Figure 7b,c). Sun et al. [15] reported that this can be due to the higher fraction of untransformed austenite at higher deformation temperatures. This phase is especially sensitive to the plastic instability phenomenon, like in pure high-Mn steels [18-20]. The type of serration observed at $100{ }^{\circ} \mathrm{C}$ was classified as a type $\mathrm{B}$. In the case of $140{ }^{\circ} \mathrm{C}$, the B and $\mathrm{C}$ types occurred with the highest amplitude and strain extent (Table 3 ).

Table 3. Detailed characteristics of serration flow at various deformation temperatures.

\begin{tabular}{cccccccc}
\hline $\begin{array}{c}\text { Deformation } \\
\text { Temperature }\left[{ }^{\circ} \mathrm{C}\right]\end{array}$ & $\begin{array}{c}\text { Serration } \\
\text { Type }\end{array}$ & $\varepsilon_{\mathrm{cr}}$ & $\begin{array}{c}\Delta \sigma+_{\max } \\
{[\mathrm{MPa}]}\end{array}$ & $\begin{array}{c}\Delta \sigma-\max \\
{[\mathrm{MPa}]}\end{array}$ & $\begin{array}{c}\overline{\Delta \sigma+} \\
{[\mathrm{MPa}]}\end{array}$ & $\begin{array}{c}\overline{\Delta \sigma-} \\
{[\mathrm{MPa}]}\end{array}$ & $\overline{\Delta \varepsilon}$ \\
\hline 60 & $\mathrm{~A}$ & 0.007 & 79 & 41 & 45 & 14 & 0.005 \\
100 & $\mathrm{~B}$ & 0.080 & 82 & 114 & 46 & 67 & 0.003 \\
140 & $\mathrm{~B}+\mathrm{C}$ & 0.060 & 129 & 126 & 68 & 64 & 0.004 \\
\hline
\end{tabular}

$\varepsilon_{\text {cr }}$-critical strain for initiation of the PLC effect

$\Delta \sigma+_{\max }$-maximum increase of the oscillation stress

$\Delta \sigma$-max - maximum decrease of the oscillation stress

$\overline{\Delta \sigma+}$-mean value of the stress increase in a range of oscillations

$\overline{\Delta \sigma-}$-mean value of the stress decrease in a range of oscillations

$\overline{\Delta \varepsilon}$-mean value of the strain period between successive oscillations

Based on the data obtained by other authors $[28,42]$, it seems that the deformation temperatures applied in the present study $\left(60-140^{\circ} \mathrm{C}\right)$ are sufficient to induce diffusion processes of solutes. As a result, it leads to the appearance of dynamic strain ageing (DSA). In general, the DSA arises from the dynamic interactions between mobile dislocations and solute atoms [15]. Jung and De Cooman [45] reported that in medium-Mn steels, this effect results from an interaction between dislocations and Mn-C clusters. They suggested that the movement of $\mathrm{C}$ atoms in Mn-C clusters between octahedral and tetrahedral interstices could lock partial dislocations in stacking faults. Hickel et al. [46] also confirmed a strong effect of Mn-C clusters on the SFE and showed that the active deformation mechanism can locally redistribute solutes and thus significantly change the local SFE. These findings concern high-Mn steels and typical medium-Mn steels covering an Mn level from 7 to $12 \%$. Moreover, the serration behavior is these steels already takes place at room temperature. In the present steel, the Mn content is limited to $5 \%$. This is presumably why the PLC effect is shifted to a post-uniform strain range and this requires at least $100{ }^{\circ} \mathrm{C}$. The serration is intensified at the higher temperature $\left(140{ }^{\circ} \mathrm{C}\right)$ with the faster carbon diffusion.

Generally, when increasing the deformation temperature, the mechanical properties of medium manganese decrease. This is related to the lower contribution of the TRIP effect, i.e., the mechanical stability of retained austenite increases $[47,48]$. Since the retained austenite amount in the present steel is relatively low $(\sim 10 \%)$, the contribution of the TRIP effect to the PLC effect cannot be significant. This is especially true at $140{ }^{\circ} \mathrm{C}$ with the lowest driving force for the strain-induced martensitic transformation [26]. This is because the stacking fault energy increases when the temperature rises [20]. Hence, the most intense PLC effect occurred at that temperature, at which the highest volume fraction of retained austenite remains mechanically stable. Finally, it resulted in a slight increase of ductility of the sample deformed at $140{ }^{\circ} \mathrm{C}$ (Table 2). Sachdev [42] reported that martensite tempering at this temperature range can also contribute to some improvement of the ductility in steels containing some martensite fraction. This phenomenon makes the work hardening and corresponding flow serration analyses more complex, and more detailed work is thus required.

\section{Conclusions}

The present study addressed the effect of deformation temperature on the work hardening behavior and corresponding PLC effect in thermomechanically processed medium-Mn steel with $1.6 \%$ $\mathrm{Al}$ content. The steel is characterized by a bainitic-martensitic microstructure with some fraction of 
retained austenite. Tensile curves show the continuous yielding behavior without the yield point phenomenon and Lüders elongation. Tensile strength reaches $1200 \mathrm{MPa}$ and ductility is limited to $10 \%$. The mechanical properties are slightly temperature-dependent, whereas the temperatures factor affects the flow behavior significantly. The flow stress serration is activated at $60{ }^{\circ} \mathrm{C}$ in an initial range of uniform deformation. The instability of plastic deformation is postponed to a post-uniform deformation range in a temperature range of $100-140^{\circ} \mathrm{C}$. The highest amplitude and range of serrations occurred at $140{ }^{\circ} \mathrm{C}$ due to the highest mechanically stable fraction of retained austenite. The delay of the serration to the post-uniform strain range is due to the Mn content being limited to $5 \%$ compared to typical medium-Mn steels.

Author Contributions: Conceptualization, A.G.; Data curation, B.G., M.M. and R.M.; Formal analysis, A.G.; Investigation, B.G., A.K., M.M., R.M. and A.G.; Methodology, B.G., A.K. and R.M.; Project administration, A.G.; Visualization, M.M.; Writing—original draft, A.K.; Writing—review \& editing, A.G.

Funding: The financial support of the National Science Center, Poland, is gratefully acknowledged, grant no. $2017 / 27 /$ B/ST8/02864.

Acknowledgments: The work was supported by statutory funds from the Faculty of Mechanical Engineering of Silesian University of Technology in 2018.

Conflicts of Interest: The authors declare no conflict of interest.

\section{References}

1. Sugimoto, K.; Tanino, H.; Kobayashi, J. Impact toughness of medium-Mn transformation-induced plasticity-aided steels. Steel Res. Int. 2015, 86, 1151-1160. [CrossRef]

2. Steineder, K.; Krizan, D.; Schneider, R.; Beal, C.; Sommitsch, C. On the microstructural characteristics influencing the yielding behavior of ultra-fine grained medium-Mn steels. Acta Mater. 2017, 139, 39-50. [CrossRef]

3. Marcisz, J.; Stępień, J. Short-time ageing of MS350 maraging steel with and without plastic deformation. Arch. Metall. Mater. 2014, 59, 513-520. [CrossRef]

4. Grajcar, A.; Radwanski, K. Microstructural comparison of the thermomechanically treated and cold deformed Nb-microalloyed TRIP steel. Mater. Tehnol. 2014, 48, 679-683.

5. Li, X.; Song, R.; Zhou, N.; Li, J. An ultrahigh strength and enhanced ductility cold-rolled medium-Mn steel treated by intercritical annealing. Scr. Mater. 2018, 154, 30-33. [CrossRef]

6. Li, Z.C.; Ding, H.; Cai, Z.H. Mechanical properties and austenite stability in hot-rolled 0.2C-1.6/3.2Al-6Mn-Fe TRIP steel. Mater. Sci. Eng. A 2015, 639, 559-566. [CrossRef]

7. Mishra, G.; Chandan, A.K.; Kundu, S. Hot rolled and cold rolled medium manganese steel: Mechanical properties and microstructure. Mater. Sci. Eng. A 2017, 701, 319-327. [CrossRef]

8. Grajcar, A.; Kilarski, A.; Kozłowska, A. Microstructure-property relationships in thermomechanically processed medium-Mn steels with increased Al content. Metals 2018, 8. [CrossRef]

9. Opiela, M. Thermomechanical treatment of Ti-Nb-V-B micro-alloyed steel forgings. Mater. Tehnol. 2014, 48, 587-591.

10. Steineder, K.; Beal, C.; Krizan, D.; Dikovits, M.; Sommitsch, C.; Schneider, R. Hot deformation behavior of a 3rd generation advanced high strength steel with a medium-Mn content. Key Eng. Mater. 2015, 651-653, 120-125. [CrossRef]

11. Opiela, M.; Grajcar, A. Hot deformation behavior and softening kinetics of Ti-V-B microalloyed steels. Arch. Civil Mechan. Eng. 2012, 12, 327-333. [CrossRef]

12. Sugimoto, K.; Hidaka, S.; Tanino, H.; Kobayashi, J. Warm Formability of 0.2 Pct C-1.5 Pct Si-5 Pct Mn Transformation-Induced Plasticity-aided steel. Metall. Mater. Trans. A Phys. Metall. Mater. Sci. 2017, 48, 2237-2246. [CrossRef]

13. Chiang, J.; Lawrence, B.; Boyd, J.D.; Pilkey, A.K. Effect of microstructure on retained austenite stability and work hardening of TRIP steels. Mater. Sci. Eng. A 2011, 528, 4516-4521. [CrossRef]

14. Callahan, M.; Hubert, O.; Hild, F.; Perlade, A.; Schmitt, J.H. Coincidence of strain-induced TRIP and propagative PLC bands in medium Mn steels. Mater. Sci. Eng. A 2017, 703, 391-400. [CrossRef] 
15. Sun, B.; Vanderesse, N.; Fazeli, F.; Scott, C.; Chen, J.; Bocher, P.; Jahazi, M.; Yue, S. Discontinuous strain-induced martensite transformation related to the Portevin-Le Chatelier effect in a medium manganese steel. Scr. Mater. 2017, 133, 9-13. [CrossRef]

16. Yang, F.; Luo, H.; Pu, E.; Zhang, S.; Dong, H. On the characteristics of Portevin-Le Chatelier bands in cold-rolled 7Mn steel showing transformation-induced plasticity. Int. J. Plast. 2018, 103, 188-202. [CrossRef]

17. Wang, X.G.; Wang, L.; Huang, M.X. Kinematic and thermal characteristics of Luders and Portevin-Le Chatelier bands in a medium Mn transformation-induced plasticity steel. Acta Mater. 2017, 124, 17-29. [CrossRef]

18. Allain, S.; Cugy, P.; Scott, C.; Chateau, J.P.; Rusinek, A.; Deschamps, A. The influence of plastic instabilities on the mechanical properties of a high-manganese austenitic FeMnC steel. Int. J. Mater. Res. 2008, 99. [CrossRef]

19. Chen, L.; Kim, H.S.; Kim, S.K.; De Cooman, B.C. Localized deformation due to Portevin-LeChatelier effect in 18Mn-0.6C TWIP austenitic steel. ISIJ Int. 2007, 47, 1804-1812. [CrossRef]

20. Lee, S.Y.; Lee, S.I.; Hwang, B. Effect of strain rate on tensile and serration behaviors of an austenitic Fe-22Mn-0.7C twinning-induced plasticity steel. Mater. Sci. Eng. A 2018, 711, 22-28. [CrossRef]

21. Wang, H.; Zhang, Y.; Yuan, G.; Kang, J.; Wang, Y.; Misra, R.D.K.; Wang, G. Significance of cold rolling reduction on Lüders band formation and mechanical behavior in cold-rolled intercritically annealed medium-Mn steel. Mater. Sci. Eng. A 2018, 737, 176-181. [CrossRef]

22. Kim, Y.; Kang, N.; Park, Y.; Choi, I.; Kim, G.; Kim, S.; Cho, K. Effects of the strain induced martensite transformation on the delayed fracture for Al-added TWIP steel. J. Korean Inst. Met. Mater. 2008, 46, 780-787.

23. Kusakin, P.S.; Kaibyshev, R.O. High-Mn Twinning Induced Plasticity Steels: Microstructure and mechanical properties. Rev. Adv. Mater. Sci. 2016, 44, 326-360.

24. Field, D.M.; Van Aken, D.C. Dynamic strain ageing phenomena and tensile response of medium-Mn TRIP steel. Metall. Mater. Trans. A 2018, 49A, 1152-1166. [CrossRef]

25. Hu, B.; Luo, H. Microstructures and mechanical properties of $7 \mathrm{Mn}$ steel manufactured by different rolling processes. Metals 2017, 7. [CrossRef]

26. Gibbs, P.J.; De Moor, E.; Merwin, M.J.; Clausen, B.; Speer, J.G.; Matlock, D.K. Austenite stability effects on tensile behavior of manganese-enriched-austenite transformation-induced plasticity steel. Metall. Mater. Trans. A 2011, 42, 3691-3702. [CrossRef]

27. Lee, S.J.; Kim, J.; Kane, S.N.; De Cooman, B.C. On the origin of dynamic strain aging in twinning-induced plasticity steels. Acta Mater. 2011, 59, 6809-6819. [CrossRef]

28. Min, J.; Hector, L.G., Jr.; Zhang, L.; Sund, L.; Carsley, J.E.; Lin, J. Plastic instability at elevated temperatures in a TRIP-assisted steel. Mater. Des. 2016, 95, 370-386. [CrossRef]

29. Ozgowicz, W.; Grzegorczyk, B.; Pawełek, A.; Wajda, W.; Skuza, W.; Piątkowski, A.; Ranachowski, Z. An analysis of the Portevin-Le Chatelier effect and cracking of CuSn6P alloy at elevated temperature of deformation applying the acoustic emission method. Eng. Fract. Mechan. 2016, 167, 112-122. [CrossRef]

30. Meng, X.; Liu, B.; Luo, L.; Ding, Y.; Rao, X.X.; Hu, B.; Liu, Y.; Lu, J. The Portevin-Le Chatelier effect of gradient nanostructured 5182 aluminum alloy by surface mechanical attrition treatment. J. Mater. Sci. Technol. 2018, 34, 2307-2315. [CrossRef]

31. Ozgowicz, W.; Grzegorczyk, B.; Pawełek, A.; Piątkowski, A.; Ranachowski, Z. Influence of the strain rate on the PLC effect and acoustic emission in single crystals of the CuZn30 alloy compressed at an elevated temperature. Mater. Tehnol. 2015, 49, 197-202. [CrossRef]

32. Górka, J. Welding thermal cycle-triggered precipitation processes in steel S700MC subjected to the thermo-mechanical control processing. Arch. Metall. Mater. 2017, 62, 321-326. [CrossRef]

33. Kurc-Lisiecka, A.; Piwnik, J.; Lisiecki, A. Laser welding of new grade of advanced high strength steel strenx 1100 MC. Arch. Metall. Mater. 2017, 62, 1651-1657. [CrossRef]

34. Sun, B.; Fazeli, F.; Scott, C.; Guo, B.; Aranas, C., Jr.; Chu, X.; Jahazi, M.; Yue, S. Microstructural characteristics and tensile behavior of medium manganese steels with different manganese additions. Mater. Sci. Eng. A 2018, 729, 496-507. [CrossRef]

35. Kamoutsi, H.; Gioti, E.; Haidemenopoulos, G.N.; Cai, Z.; Ding, H. Kinetics of solute partitioning during intercritical annealing of a medium-Mn steel. Metall. Mater. Trans. A 2015, 46, 4841-4846. [CrossRef]

36. Cottrell, A.H. A note on the Portevin-le Chatelier effect. Lond. Edinb. Dublin Philos. Mag. J. Sci. 1953, 44, 829-832. [CrossRef] 
37. Mc Cormick, P.G. Theory of flow localization due to dynamic strain ageing. Acta Mater. 1988, 36, 3061-3067. [CrossRef]

38. Grajcar, A.; Skrzypczyk, P.; Kozłowska, A. Effects of temperature and time of isothermal holding on retained austenite stability in medium-Mn steels. Appl. Sci. 2018, 8. [CrossRef]

39. Gomez, M.; Garcia, C.I.; De Ardo, A.J. The role of new ferrite on retained austenite stabilization in Al-TRIP steels. ISIJ Int. 2010, 50, 139-146. [CrossRef]

40. Jacques, P.J.; Girault, E.; Mertens, A.; Verlinden, B.; Van Humbeeck, J.; Delannay, F. The developments of cold-rolled TRIP-assisted multiphase steels. Al-alloyed TRIP-assisted multiphase steels. ISIJ Int. 2001, 41, 1068-1074. [CrossRef]

41. Soliman, M.; Palkowski, H. On factors affecting the phase transformation and mechanical properties of cold-rolled transformation-induced-plasticity-aided steel. Metall. Mater. Trans. A 2008, 39, 2513-2527. [CrossRef]

42. Sachdev, A.K. Dynamic strain aging of various steels. Metall. Trans. A 1982, 13, 1793-1797. [CrossRef]

43. Aydemir, B.; Zeytin, H.K.; Guven, G. Investigation of Portevin-Le Chatelier effect of hot-rolled Fe-13Mn-0.2C-1Al-1Si TWIP steel. Mater. Tehnol. 2016, 50, 511-516. [CrossRef]

44. Kral, L.; Million, B.; Cermak, J. Diffusion of carbon and manganese in Fe-Mn-C. Defect Diffus. Forum 2007, 263, 153-158. [CrossRef]

45. Jung, I.C.; De Cooman, B.C. Temperature dependence of the flow stress of Fe-18Mn-0.6C-xAl twinning-induced plasticity steel. Acta Mater 2013, 61, 6724-6735. [CrossRef]

46. Hickel, T.; Sandlöbes, S.; Marceau, R.K.W.; Dick, A.; Bleskov, I.; Neugebauer, J.; Raabe, D. Impact of nanodiffusion on the stacking fault energy in high-strength steels. Acta Mater. 2014, 75, 147-155. [CrossRef]

47. Kim, H.; Lee, J.; Barlat, F.; Kim, D.; Lee, M.G. Experiment and modeling to investigate the effect of stress state, strain and temperature on martensitic phase transformation in TRIP-assisted steel. Acta Mater. 2015, 97, 435-444. [CrossRef]

48. Zhang, M.; Li, L.; Ding, J.; Wu, Q.; Wang, Y.D.; Almer, J.; Guo, F.; Ren, Y. Temperature-dependent micromechanical behavior of medium-Mn transformation-induced-plasticity steel studied by in situ synchrotron X-ray diffraction. Acta Mater. 2017, 141, 294-303. [CrossRef]

(C) 2018 by the authors. Licensee MDPI, Basel, Switzerland. This article is an open access article distributed under the terms and conditions of the Creative Commons Attribution (CC BY) license (http:/ / creativecommons.org/licenses/by/4.0/). 